\title{
PTU-053 $\star$ VASCULAR RISK PROFILE IN INCIDENT COELIAC DISEASE AND CHANGE WITH GLUTEN-FREE DIET
}

doi:10.1136/gut.2011.239301.181

N R Lewis, ${ }^{1 *}$ R F Logan, ${ }^{1}$ D S Sanders, ${ }^{2}$ R B Hubbard, ${ }^{1}$ G K Holmes, ${ }^{3}$ J West ${ }^{1}$ Division of Epidemiology, University of Nottingham, Nottingham, UK; ${ }^{2}$ Division of Gastroenterology and Hepatology, Royal Hallamshire Hospital, Sheffield, UK; ${ }^{3}$ Division of Gastroenterology, Royal Derby Hospitals, Derby, UK

Introduction Vascular disease is the most common cause of mortality in coeliac disease. ${ }^{1}$ Despite recent studies observing people with diagnosed coeliac disease have lower total cholesterol and are less likely to have a diagnosis of hypertension, 
coeliac disease does not appear to have a protective effect upon vascular disease events ${ }^{2}$ with even increased risks observed. ${ }^{3}$ Concern has been raised as to whether treatment of coeliac disease may have an adverse effect on vascular risk profile. Our aim was to describe the vascular risk profile in adults newly diagnosed with coeliac disease and to observe any change in the profile following treatment with a glutenfree diet (GFD).

Methods We measured the vascular risk profile at diagnosis and compared this with Health Survey for England (HSE) figures, and again following 12 months treatment with GFD in 151 adults newly diagnosed with coeliac disease between 2007 and 2008 at Nottingham, Sheffield and Derby. Paired t-tests were used to examine changes in anthropometric, vital signs and blood variables from baseline in incident coeliacs to following 12 months with GFD. Unpaired t tests were used to examine any difference in the mean anthropometric and serum values, standardised for age and sex, between the coeliac cohort and HSE control cohort.

Results Newly diagnosed coeliacs had significantly lower total, HDL and LDL cholesterol than the general population (table 1). Incident coeliacs were as likely as the general population to smoke though were twice as likely to have raised waist: hip circumference (O:E 1.6 (95\% CI 1.1 to 2.2). Male incident coeliacs were twice as likely to have measured hypertension as general population (O:E 1.9 (95\% CI 1.2 to 2.5$) .56 \%$ of males and $36 \%$ of females were overweight or obese as defined by BMI at diagnosis of coeliac disease. Following 12 months treatment with GFD, there was a mean $2.3 \mathrm{~cm}(95 \%$ CI 1.7 to $2.8)$ increase in waist circumference though no significant rise in total or LDL cholesterol.

Table 1 PTU-053 Vascular risk profile at diagnosis of coeliac disease and following treatment

\begin{tabular}{|c|c|c|c|c|}
\hline Cholesterol profile (mmol/L) & $\mathbf{N}$ & $\begin{array}{l}\text { Incident } \\
\text { coeliac } \\
\text { disease }\end{array}$ & $\begin{array}{l}\text { General } \\
\text { population }\end{array}$ & $\begin{array}{l}\text { Mean difference } \\
(95 \% \mathrm{Cl})\end{array}$ \\
\hline \multicolumn{5}{|l|}{ Mean total cholesterol } \\
\hline Men & 57 & $4.2(1.3)$ & $5.30(1.2)$ & $-1.1(-0.8$ to -1.4$)$ \\
\hline Women & 94 & $4.6(2.3)$ & $5.40(1.2)$ & $-0.8(-0.5$ to -1.1$)$ \\
\hline \multicolumn{5}{|l|}{ Mean HDL cholesterol } \\
\hline Men & 56 & $1.1(0.5)$ & $1.3(0.6)$ & $-0.2(-0.1$ to -0.4$)$ \\
\hline Women & 89 & $1.3(0.8)$ & $1.6(0.6)$ & $-0.3(-0.2$ to -0.4$)$ \\
\hline \multicolumn{5}{|l|}{ Mean LDL cholesterol } \\
\hline Men & 40 & $2.3(0.9)$ & $3.6(0.9)$ & $-1.3(-1.0$ to -1.6$)$ \\
\hline Women & 46 & $2.9(0.9)$ & $3.6(0.9)$ & $-0.7(-0.4$ to -1.0$)$ \\
\hline
\end{tabular}

Conclusion The observed vascular risk profile suggests both protective and adverse associations of incident coeliac disease with subsequent exposure to a gluten-free diet resulting in an attenuation or indeed reversal of the vascular risk profile in some co-variates.

Competing interests None.

Keywords Coeliac Disease.

\section{REFERENCES}

1. Peters U, Askling J, Gridley G, et al. Causes of death in patients with celiac disease in a population-based Swedish cohort. Arch Intern Med 2003;163:1566-72.

2. West J, Logan RF, Card, et al. Risk of vascular disease in adults with diagnosed coeliac disease: a population-based study. Alimentary Pharmacology and Therapeutics 2004;20:73-9.

3. Ludvigsson J, de Faire U, Ekbom A, et al. Vascular disease in a population-based cohort of individuals hospitalised with coeliac disease Heart 2007;93:1111-15. 